\title{
Synthesis, Structural Properties and Complex Corrosion Inhibition Cu (II) With Amino Acid (DL- $\alpha$-Alanine)
}

\author{
N. GHARDA ${ }^{1}$, M. GALAl ${ }^{2, *}$, L. SAQALLI ${ }^{1}$, \\ M. OUAKKI ${ }^{3}$, N. HABBADI ${ }^{1}$, R. GHAILANE ${ }^{1}$, A. SOUIZI ${ }^{1}$, \\ M. EBN TOUHAMI ${ }^{2}$ and Y. PERES-LUCCHESE ${ }^{4}$ \\ 'Laboratoire de Synthèse Organique, Organométallique et Théorique, Université lbn \\ Tofail Faculté des sciences, B.P 133, Kenitra, Maroc. \\ 2Laboratory of Materials Engineering and Environment: Modeling and Application, Faculty of \\ Science, University IbnTofail BP. 133-14000, Kenitra, Morocco. \\ ${ }^{3}$ Laboratory of materials, electrochemistry and environment, Faculty of Science, IbnTofail \\ University, PB 133-14050 Kénitra,Morocco. \\ ${ }^{4}$ Laboratoire de génie chimique UMR/UPS, Toulouse, France. \\ ${ }^{*}$ Corresponding author E-mail: galaimouhsine@gmail.com \\ http://dx.doi.org/10.13005/ojc/330410
}

(Received: May 08, 2017; Accepted: June 15, 2017)

\begin{abstract}
We began, in this work, by the synthesis of the $\mathrm{Cu}(\mathrm{II})$ complex with $\mathrm{DL}-\alpha$-alanine which is characterized by powder X-ray diffraction, the UV-visible spectroscopy and the infrared spectroscopy. The RXs show that the complex has the formula $\mathrm{C}_{6} \mathrm{H}_{12} \mathrm{~N}_{2} \mathrm{O}_{4} \mathrm{Cu}, 2 \mathrm{H}_{2} \mathrm{O}$ while the experimental data show that the ligand is bidentate and the studied complex adopts octahedral stereochemistry. We then studied the inhibitory effect of Bis (DL- $\alpha$-alaninato) copper dihydrate complex on ordinary steel in $1 \mathrm{M}$ $\mathrm{HCl}$ solution. The corrosion inhibition study of this complex was carried out by the electrochemical method (stationary and transient). The measurements carried out by this method gave a maximum efficiency of $88 \%$ to $10^{-5} \mathrm{M}$ of Bis (DL- $\alpha$-alaninato) copper dihydrate complex on an ordinary steel surface of 1 to $2 \mathrm{~cm}$ dimension in the presence of a $1 \mathrm{M} \mathrm{HCl}$ solution. The obtained results show that the adsorption process of the Bis (DL- $\alpha$-alaninato) copper dihydrate complex on the metal surface obeys the Langmuir adsorption isotherm.
\end{abstract}

Keywords:Bis (DL- $\alpha$-alaninato) copper dihydrate, Corrosion, Inhibitor, $1 \mathrm{M} \mathrm{HCl}$.

\section{INTRODUCTION}

Copper is an essential element for many life forms since it is present in plants, animals and it used in various application industriel ${ }^{1,2}$. This metal forms stable complexes with amino acids ${ }^{3}$.
The latter have both the amine function and the carboxylic acid function. The general formula in most cases is $\mathrm{H} 2 \mathrm{~N} \mathrm{CH} \mathrm{R} \mathrm{COOH}$ where $R$ is an organic substituent which is known under the name "side chain") $)^{4,5}$. Nine of the 20 standard amino acids are called "essential" amino acids for 
human beings as long as they cannot be created from other compounds. They should be taken as food supplements ${ }^{6,7}$. Others may be conditionally essential for certain ages or medical conditions ${ }^{8-10}$.

Amino acids, which represent the unity of proteins, are attractive because they can bind to metal cations like other organic ligands which are rich in coordination sites (one or two carboxylic groups, amino group). Moreover, their mode of coordination is flexible (monodentate, bidentate or tridentate ligands) ${ }^{11}$.

The current interest in $\mathrm{Cu}$ complexes derives from their potential use as antimicrobial, antiviral, anti-inflammatory, anti-tumor agents, enzyme inhibitors, and chemical nucleases ${ }^{12}$.

The literature studying the effect of metal complexes as an inhibitor of steel corrosion in an acidic solution is very limited ${ }^{13-16}$.

Corrosion is a phenomenon of degradation of metallic materials by the environment ${ }^{17}$. This phenomenon concerns most industrial sectors, notably the aeronautics industry, the automotive industry and the chemical and petrochemical industries ${ }^{18}$ in which the economic stakes are therefore considerable. Corrosion is not only a source of wastage of raw materials and energy but can also cause serious accidents and therefore contributes to environmental pollution ${ }^{19}$.

The use of low-concentration inhibitors is one of the most practical methods for protecting and limiting the attack of metallic materials, which is easy to implement and inexpensive $e^{20,21}$. Acid solutions are widely used in industry, with the main areas of application being steel pickling, cleaning of facilities, stimulation of oil wells, and crude oil refining ${ }^{22,23}$. As an acid medium, $\mathrm{HCl}$ is one of the most widely used agents in many industrial processes, causing metal degradation due to its aggressiveness, either by chemical or electrochemical reactions.

Our objective is to synthesize the Bis (DL- $\alpha$-alaninato) copper dihydrate complex from ligand alanine with good yield. This complex has the advantage of being soluble in aqueous media. After purification, the complex is analyzed by powder
X-ray diffraction, the UV-visible spectroscopy and the infrared spectroscopy. The inhibitory efficacy of Bis (DL- $\alpha$-alaninato) copper dihydrate reaches a maximum value of $88 \%$ at $10-5 \mathrm{M}$.

\section{MATERIALS AND METHODS}

\section{Instruments}

Infrared spectra (KBr disks) were recorded IRTF Vertex 70 Infrared Spectrophotometer in the range of 4000 to $400 \mathrm{~cm}^{-1}$.

The UV-visible spectrophotometric studies were performed in the range of $200-800 \mathrm{~nm}$ by using an SP-2000UV Spectrophotometer with a $1 \mathrm{~cm}$ cell at a concentration of 10-3 $\mathrm{M}$ in water at room temperature.

The studied phase was characterized by $\mathrm{X}$-ray powder diffraction and the diffractogram was recorded at room temperature on a pure sample by using a PANalytical X'Pert3 Powder diffractometer, which operates with copper $\mathrm{K} \alpha$ radiation $(\lambda=1.5406 \AA)$.

The preparation of the $\mathrm{Cu}$ (II) complex with the amino acid (DL- $\alpha$-alanine)

The Bis (DL- $\alpha$-alaninato) copper dihydrate was synthesized according to the classical literature method $^{24}$.

This complex is prepared with stirring at room temperature. $1.8067 \mathrm{~g}\left(2.0310^{-2} \mathrm{~mol}\right)$ of alanine dissolved in $20 \mathrm{ml}$ of water was introduced into an erlenmeyer flask. $2.0503 \mathrm{~g}\left(2.0310^{-2} \mathrm{~mol}\right)$ of triethylamin was added to deprotonate the amino acid.

A solution consisting of $2.6862 \mathrm{~g}$ $\left(1.1110^{-2} \mathrm{~mol}\right)$ of copper chloride hexahydrate in $10 \mathrm{ml}$ of water was added dropwise with the aid of a burette. When the addition was complete, the reaction is kept under stirring at room temperature for 4 hours.

A precipitate formed. The blue precipitate was filtered on a frit with a vacuum flask and washed with ethanol. A blue powder was obtained and was dried in an oven at $60^{\circ} \mathrm{C}$. The calculated yield from the obtained dry powder is equal to $86 \%$. 
The obtained solid was recrystallized from a mixture (1/2) $\mathrm{H}_{2} \mathrm{O} / \mathrm{MeOH}$, blue crystals appear.

Analytical Results: Found: C, 26.13; $\mathrm{Cu}$, 23.04; $\mathrm{H}, 5.85 ; \mathrm{N}, 10.16 ; \mathrm{O}, 34.81$ Calculated for $\mathrm{Cu}$ (C3H6NO2)2, 2H2O: C, 26.13; Cu, 23.06; H, 5.81; N, $10.16 ;$ O, 34.84\%.

The complexing reaction of $\mathrm{Cu}$ (II) with DL- $\alpha$-alanine can be represented as follows:

\section{The used materials}

The material used in corrosion study is an ordinary steel whose chemical composition (\%) is given in Table 1.

\section{Solution}

The Bis (DL- $\alpha$-alaninato) copper dihydrate is used as an inhibitor in $1 \mathrm{M} \mathrm{HCl}$ solution, prepared from commercial solution, hydrochloric acid (37\%) by using double distilled water. The concentrations used for the inhibitor range from $10^{-3}$ to $10^{-6} \mathrm{M}$.

\section{Electrochemical measurements}

The electrochemical experiments are carried out in a pyrex cell equipped with a conventional three-electrode assembly: steel $(1 \mathrm{~cm} 2)$ as working electrode (ET), platinum as auxiliary electrode and $\mathrm{Ag} / \mathrm{AgCl}$ electrodes as reference electrodes.

The intensity-potential curves are obtained in the potentiodynamic mode. The potential applied to the sample varies continuously with a scanning rate of $1 \mathrm{MV} / \mathrm{s}$. We have chosen a relatively low scanning speed so as to be in the quasi-stationary mode. The measurements are made with a mounting including a galvanostat potentiometer PGZ100, of radiometer type, associated with the Voltamaster 4 software. Before the curves are plotted, the working electrode is maintained for 30 minutes at its abort potential. We first plotted the cathodic curves and then the anodic curves.

\section{RESULTS AND DISCUSSIONS}

Analyzing methods of the Bis (DL- $\alpha$-alaninato) complex copper dihydrate

The structure of the complex was determined from the following spectral data: IR spectroscopy, UVvisible spectroscopy and X-ray powder diffraction.

\section{Infrared Spectroscopy}

The main infrared absorption bands (in $\mathrm{cm}^{-1}$ ) of ligand and complex are shown in Table 2. The characteristic bands are in agreement with the data of the literature ${ }^{25-31}$.

The examination of the IR spectrum of complex in comparison with corresponding ligand made it possible to notice the following points:

- $\quad$ The IR spectra of amino acids show localized bands in the $2934-3037 \mathrm{~cm}^{-1}$ region attributed to elongation vibrations $v(\mathrm{~N}-\mathrm{H})^{25}$

- $\quad$ The wave numbers in the $1393-1415 \mathrm{~cm}^{-1}$ and 1583-1664 $\mathrm{cm}^{-1}$ domains correspond to symmetrical and asymmetric elongation
(2)<smiles>NC(I)C(=O)O</smiles>

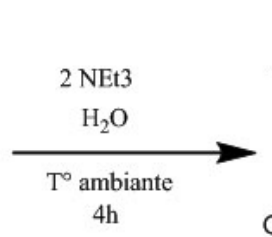

$4 \mathrm{~h}$

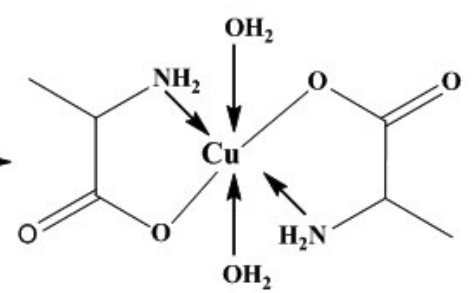

$86 \%$

Scheme 1: reaction of the complexation of alanine with copper

Table 1: Mass Chemical Composition of Ordinary Steel

\begin{tabular}{lllllllllllll}
\hline Elements & C & Si & Mn & Cr & Mo & Ni & Al & Cu & Co & V & W & Fe \\
\hline$(\%)$ of Mass & 0.11 & 0.24 & 0.47 & 0.12 & 0.02 & 0.1 & 0.03 & 0.14 & $<0.0012$ & $<0.003$ & 0.06 & Balance \\
\hline
\end{tabular}


vibrations respectively involving the carboxylic group $\mathrm{COO}^{-25,26}$.

In the [Bis (DL- $\alpha$-alaninato) copper dihydrate.complex, the $\mathrm{NH} 2$ functional band is shifted towards $3158.5 \mathrm{~cm}^{-1}$, which proves that the binding of the $-\mathrm{NH} 2$ group in the complex is formed ${ }^{27}$. In alanine, two absorptions related to the two asymmetric and symmetric vibration modes are characteristic of the carboxyl ion $\mathrm{COO}^{-28}$. In the alanine complex, the asymmetric $v(C=O)$ vibration band moves from 1593 to $1625 \mathrm{~cm}^{-1}$ and the symmetrical vibrating band $v(\mathrm{C}=\mathrm{O})$ moves from 1410 to $1395 \mathrm{~cm}^{-1}$. The slipping of the position of the bands $v(\mathrm{C}=\mathrm{O})$ as and $v(\mathrm{C}=\mathrm{O})$ $s$ in the complex with respect to the ligand suggests that alanine is coordinated with copper by the COO- group ${ }^{29,30}$.

- The elongation vibrations of the $\mathrm{O}-\mathrm{H}$ function corresponding to the $\mathrm{Cu}$ water coordination are in the range of $3586-3384 \mathrm{~cm}^{-131}$.

- $\quad$ Two other bands appear at lower energies. The first at $408.3 \mathrm{~cm}^{-1}$ assigned to the (Cu-O) bond and the second at low intensity at $584.6 \mathrm{~cm}^{-1}$ characterizes the binding $(\mathrm{Cu}-\mathrm{N})^{31}$.

\section{The UV-visible spectrophotometry}

The electron spectrum of copper (II) complex with alanine was recorded in water at the concentration of $10^{-3} \mathrm{M}$. The obtained results are summarized in Table 3.

The UV-Visible electron spectrum of the ligand in water has two bands: one at $322 \mathrm{~nm}$ and the other at $389 \mathrm{~nm}$. This bands are attributed to the transition $\left(\mathrm{n} \rightarrow \pi^{\star}\right)^{32}$.

The UV-Visible electron spectrum of the $\mathrm{Cu}$ (II) complex shows the following bands at 389 , 441 and $620 \mathrm{~nm}$. The first band is attributed to ligand-metal charge transfer $(L \rightarrow M)$, while the last two bands are attributed to the transitions $d-d$ $\left({ }^{2} \mathrm{Eg}{ }^{2} \mathrm{~T}_{2} \mathrm{~g}\right)$. This transition is characteristic of an octahedral geometry ${ }^{33,34}$.

\section{X-ray diffraction study}

The experimental powder diffraction pattern is depicted in Figure 1. Indexing results show Bis(DL- $\alpha$-alaninato) copper dihydrate complex is monoclinic with space group $\mathrm{C} 2$ and unitcell parametersa $=12.0862(9) \AA, b=9.6048(9) \AA$,

Table 2: the main infrared absorption bands of ligand (alanine) and complex (Bis (DL- $\alpha$-alaninato) copper dihydrate)

\begin{tabular}{cllll}
\hline \multicolumn{2}{c}{ ligand } & \multicolumn{2}{c}{ complex } \\
\cline { 2 - 5 } bands & experimental & literature & experimental & literature \\
\hline$v(\mathrm{O}-\mathrm{H})$ & - & - & 3394,9 & $3586-3384$ \\
$\left(\mathrm{H}_{2} \mathrm{O}\right)$ & & & & 3085 \\
$v(\mathrm{~N}-\mathrm{H})$ & 3087 & $2934-3037$ & 3158,5 & $1646-1609$ \\
$v_{\text {as }}(\mathrm{C}=\mathrm{O})$ & 1593 & $1583-1664$ & 1625,1 & 1396 \\
$v(\mathrm{C}=\mathrm{O})$ & 1410 & $1393-1415$ & 1395 & $589-576$ \\
$v(\mathrm{Cu}-\mathrm{O})$ & - & - & 584,6 & 423 \\
$v(\mathrm{Cu}-\mathrm{N})$ & - & - & 408,3 & \\
\hline
\end{tabular}

Table 3: The main bands of the ligand and the complex electron spectrum

\begin{tabular}{llll}
\hline & $\lambda_{\max }(\mathrm{nm})$ & $\varepsilon_{\max }\left(\mathrm{I} \cdot \mathrm{mol}^{-1} \cdot \mathrm{cm}^{-1}\right)$ & Transition \\
\hline \multirow{2}{*}{ Ligand } & 322 & 7 & $\mathrm{n} \rightarrow \pi *$ \\
& 389 & 31 & $\mathrm{n} \rightarrow \pi *$ \\
Complex & 620 & 62 & $\mathrm{~d}-\mathrm{d}$ \\
& 441 & 37 & $\mathrm{~d}-\mathrm{d}$ \\
& 389 & 74 & $\mathrm{~L} \rightarrow \mathrm{M}$ \\
\hline
\end{tabular}


$C=8.9915(6) \AA, \quad \beta=110.887(3)^{\circ}$, unit-cell volume $V=975.19 \AA^{3}, Z=4$, and space group C2 (Table 4). After Pawley refinement, the unit-cell parameters of $\mathrm{Bis}(\mathrm{DL}-\alpha$-alaninato) copper dihydrate complex were solved. All lines of powder data were indexed and consistent with the $\mathrm{C} 2$ space group.

\section{Electrochemical study Polarization curves}

Fig1 shows the polarization curves of the ordinary steel in $1 \mathrm{M} \mathrm{HCl}$ in the absence and presence of Bis (DL- $\alpha$-alaninato) copper dihydrate at various concentrations ranging from $10^{-3}$ to $10^{-6}$ $\mathrm{M}$ at $298 \mathrm{~K}$. follows:

The (EI\%) inhibition efficiency is defined as

$$
\mathrm{EI} \%=\frac{\mathrm{i}_{\text {corr }}-\mathrm{i}_{\text {corr } / \text { inh }}}{\mathrm{i}_{\text {corr }}} \times 100
$$

Where icorr and icorr / inh are the corrosion current densities in the absence and in the presence of the inhibitor respectively, obtained by extrapolating the cathodic and anodic Tafel line to the corrosion potential (Ecorr).

Fig 2 illustrates the cathodic and the anodic polarization curves of ordinary steel in $1 \mathrm{M} \mathrm{HCl}$ in the absence and the presence of the Bis (DL- $\alpha$ alaninato) copper dihydrate complex at different concentrations. The analysis of these polarization curves shows that adding the complex causes a shift in corrosion potential towards more cathodic values. This displacement is accompanied by a marked reduction in the cathodic current densities.
It is clear from Table 5 that the cathodic current density decreases with decreasing the inhibitor concentration to one at a concentration of $10^{-5} \mathrm{M}$, which indicates the inhibition of the reaction of the hydrogen release. It can be concluded that this is a cathodic inhibitor, and the parallel cathode Tafel curves show that the evolution of hydrogen is controlled by the pure activation mechanism ${ }^{37,38}$.

The electrochemical parameters as well as the inhibitory efficiency obtained from the polarization curve are given in Table 5. We notice that the inhibitory power of the complex tested increases with the decrease of the concentration to reach a maximum value of $88 \%$ at $10^{-5} \mathrm{M}$.

\section{Study by the electrochemical impedance spectroscopy (EIS)}

We used the techniques of EIS to confirm the results which were obtained by the polarization curves and to have more information about the mechanism of corrosion of ordinary steel.

The inhibition efficiency is evaluated from the transfer resistance (ERct\%) which is defined by using the following equation:

$$
E_{R_{c t}} \%=\frac{R_{c t / i n h}-R_{c t}}{R_{c t / i n h}} \times 100
$$

Where Rct / inh and Rt are the charge transfer resistors in the presence and the absence of the inhibitor respectively.

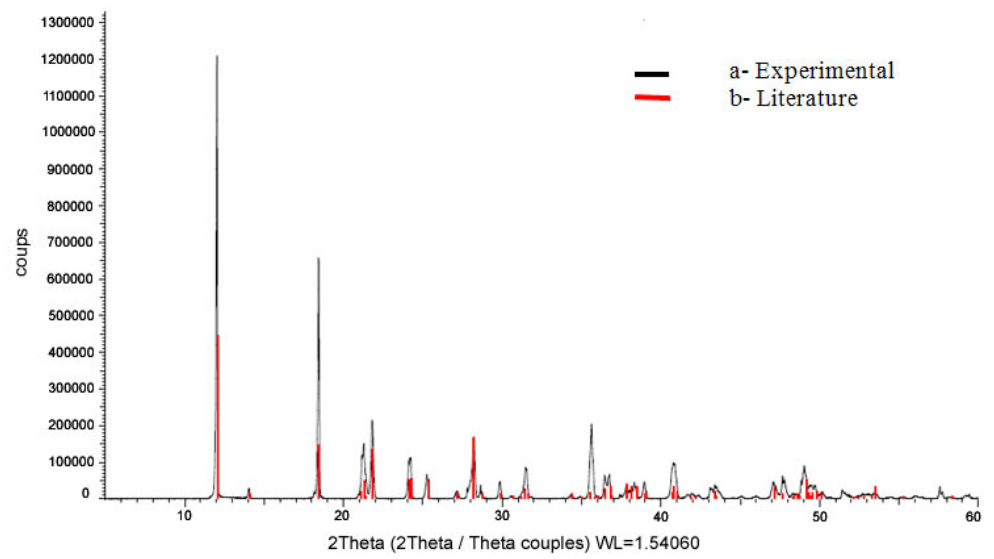

Fig. 1: X-ray powder diffraction pattern of (a) Bis(DL- $\alpha$-alaninato) copper dihydrate complex experimental and (b) literature ${ }^{35,36}$ 
The impedance spectra for ordinary steel in $1 \mathrm{M} \mathrm{HCl}$ with and without the Bis (DL- $\alpha$-alaninato) copper dihydrate complex at different concentrations and at $298 \mathrm{~K}$ are shown in the form of the Nyquist diagrams which is given in Fig 3 . According to the diagrams, we find that for all concentrations, there is a single capacitive loop corresponding to the charge transfer resistance whose diameter increases with the decrease in the concentration of the Bis (DL-a-alaninato) copper dihydrate complex.

The results in Table 6 are showing that:

The charge transfer resistance increases with decreasing concentration of the Bis (DL- $\alpha$ alaninato) copper dihydrate complex to one at a concentration of $10^{-5} \mathrm{M}$ while the capacity of the double layer decreases. This decrease in Cdl is due to the adsorption of the inhibitor on the surface of the steel.

The inhibitory efficiency increases with the decrease of the concentration of the inhibitor to reach a maximum value of $87 \%$ at $10^{-5} \mathrm{M}$.

\section{Adsorption Isotherm}

The recovery rate values $(\theta)$ for the different complex concentrations, which are obtained from the electrochemical measurements of the 298 $\mathrm{K}$ temperature bias curves (Table 5), were used to determine the isotherm corresponding to the adsorption process of the complex. Thus, different isotherm corresponding to Langmuir, Temkin and Frumkin were tested to find the suitable adsorption isotherm (Fig 4, 5 and 6). These adsorption isotherms

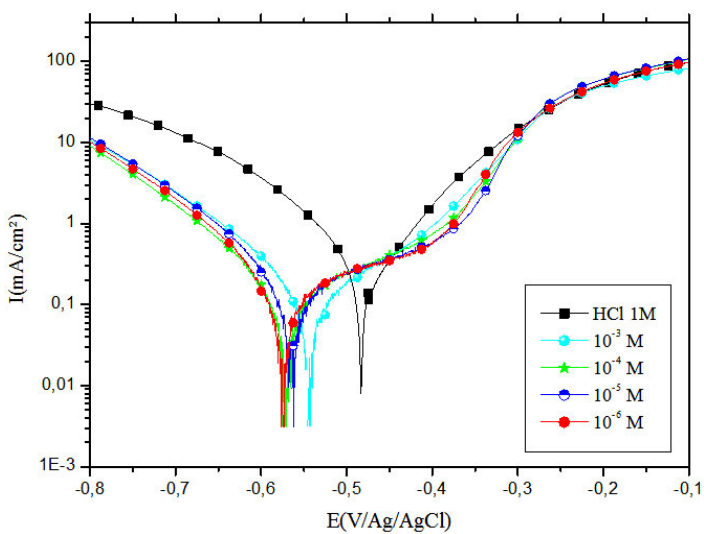

Fig. 2: The polarization curves of ordinary steel in $1 \mathrm{M} \mathrm{HCl}$ at different concentrations of Bis (DL- $\alpha$-alaninato) copper dihydrate at $\mathrm{T}=298 \mathrm{~K}$ were used for other inhibitors [39. . According to these isotherms, $\theta$ is connected to the inhibitor concentration Cinh by the following equations:

$$
\frac{C_{i n h}}{\theta}=\frac{1}{K_{a d s}}+C_{i n h}
$$

(Langmuir adsorption isotherm)

$$
\exp (-2 a \theta)=k C_{i n h^{\prime}}
$$

(Temkin adsorption isotherm)

$$
\frac{\theta}{1-\theta} \exp (-2 a \theta)=k C_{i n h}
$$

(Frumkin adsorption isotherm)

Where $a$ is an interaction constant between adsorbed particles, $\mathrm{K}_{\text {ads }}$ is the equilibrium constant of the adsorption process and $\mathrm{C}_{\text {inh }}$ is the concentration of the inhibitor in the electrolyte.

The $\theta$ values are present graphically according to the suitable adsorption isotherm. Only the Cinh/ $\theta$ curve in view of the concentration is linear with a correlation coefficient greater than 0.99 for the complex (Fig 4), which shows that the adsorption of the complex on the steel surface in the hydrochloric medium obeys to the adsorption isotherm of Langmuir.

\section{Temperature effect}

Temperature is one of the factors which

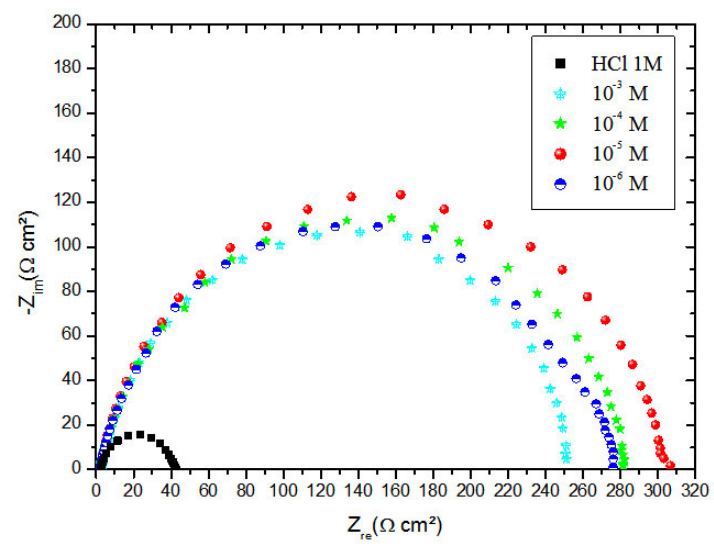

Fig. 3: Diagrams of electrochemical impedance of ordinary steel in $1 \mathrm{M} \mathrm{HCl}$ in the absence and the presence of the complex at different concentrations and at $298 \mathrm{~K}$ 
Table.4: Indexed X-ray powder diffraction data of Bis (DL- $\alpha$-alaninato) copper dihydrate complex, $\mathrm{C} 6 \mathrm{H} 12 \mathrm{Cu} \mathrm{N} 2 \mathrm{O} 4 \cdot 2 \mathrm{H} 2 \mathrm{O}$. Only the peaks with $\mathrm{I}_{\text {obs }}$ of 1 or greater are reported

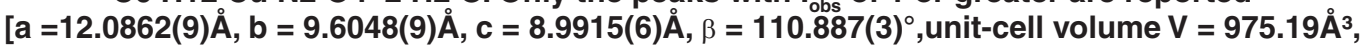
$Z=4$, and space group C2. All measured lines were indexedand are consistent with the C2 space group. The d-values were calculated using CuKá1 radiation $(\theta=1,54056 \AA ̊)$.

\begin{tabular}{|c|c|c|c|c|c|c|c|c|}
\hline $2 \theta_{\text {obs }}\left({ }^{\circ}\right)$ & $d_{o b s}(\AA)$ & $I_{\text {obs }}$ & $\mathbf{h}$ & $\mathbf{k}$ & I & $2 \theta_{\text {cal }}\left({ }^{\circ}\right)$ & $\mathrm{d}_{\mathrm{cal}}(\AA)$ & $\Delta 2 \theta$ \\
\hline 12.0740 & 7.324090 & 100 & 1 & 1 & 0 & 11.7590 & 7.519521 & 0.315 \\
\hline 14.0790 & 6.285250 & 3 & 1 & 1 & -1 & 13.0697 & 6.76824 & 1.009 \\
\hline 18.4530 & 4.804110 & 33 & 0 & 2 & 0 & 18.4590 & 4.8024 & -0.006 \\
\hline 21.1280 & 4.201520 & 5 & 0 & 0 & 2 & 19.7309 & 4.49575 & 1.397 \\
\hline 21.2860 & 4.170690 & 11 & 0 & 2 & 1 & 20.9492 & 4.23605 & 0.336 \\
\hline 21.3740 & 4.153710 & 2 & 2 & 0 & -2 & 24.6609 & 3.60705 & -3.286 \\
\hline 21.8070 & 4.072210 & 30 & 1 & 1 & -2 & 23.0271 & 3.85868 & -1.220 \\
\hline 24.1640 & 3.680070 & 12 & 2 & 2 & -1 & 25.6601 & 3.46872 & -1.496 \\
\hline 24.3050 & 3.659040 & 13 & 2 & 2 & 0 & 23.6437 & 3.75976 & 0.661 \\
\hline 25.3890 & 3.505220 & 12 & 3 & 1 & 0 & 23.9324 & 3.71515 & 1.456 \\
\hline 27.1690 & 3.279470 & 3 & 3 & 1 & -2 & 31.2056 & 2.86384 & -4.036 \\
\hline 28.1970 & 3.162200 & 37 & 0 & 2 & 2 & 27.1474 & 3.28203 & 1.049 \\
\hline 28.7520 & 3.102410 & 3 & 2 & 2 & 1 & 25.6606 & 3.46872 & 3.091 \\
\hline 29.8800 & 2.987810 & 3 & 1 & 3 & -1 & 30.5225 & 2.92636 & -0.642 \\
\hline 31.2160 & 2.862920 & 1 & 4 & 0 & -2 & 35.7757 & 2.50778 & -4.559 \\
\hline 31.4290 & 2.844000 & 6 & 1 & 1 & -3 & 32.1225 & 2.78415 & -0.693 \\
\hline 31.6641 & 2.823420 & 3 & 4 & 0 & 0 & 29.5387 & 3.02155 & 2.125 \\
\hline 34.3560 & 2.608100 & 3 & 1 & 3 & -2 & 35.1750 & 2.54922 & -0.819 \\
\hline 35.0609 & 2.557260 & 1 & 4 & 2 & -1 & 36.4966 & 2.45989 & -1.435 \\
\hline 35.5570 & 2.522710 & 4 & 2 & 2 & -3 & 38.3761 & 2.34362 & -2.819 \\
\hline 35.8589 & 2.502160 & 1 & 3 & 3 & 2 & 41.2006 & 2.18924 & -5.341 \\
\hline 36.0570 & 2.488870 & 2 & 2 & 2 & -2 & 30.9806 & 2.88412 & 5.076 \\
\hline 36.5080 & 2.459150 & 6 & 4 & 2 & 0 & 35.0581 & 2.55745 & 1.449 \\
\hline 37.8390 & 2.375650 & 9 & 1 & 3 & -2 & 35.1750 & 2.54922 & 2.663 \\
\hline 38.1150 & 2.359080 & 8 & 3 & 3 & 2 & 41.2006 & 2.18924 & -3.085 \\
\hline 38.9740 & 2.309040 & 3 & 0 & 4 & -2 & 42.6524 & 2.11802 & 3.678 \\
\hline 39.0560 & 2.304380 & 5 & 5 & 1 & -1 & 39.7027 & 2.26832 & -0.646 \\
\hline 40.7101 & 2.214490 & 4 & 2 & 4 & 0 & 40.3862 & 2.23149 & 0.323 \\
\hline 41.8839 & 2.155100 & 1 & 1 & 1 & -4 & 41.9123 & 2.15370 & -1.001 \\
\hline 42.1500 & 2.142110 & 1 & 3 & 1 & 2 & 31.2056 & 2.86384 & 10.94 \\
\hline 43.3740 & 2.084450 & 5 & 0 & 4 & -2 & 42.6525 & 2.11802 & 0.721 \\
\hline 48.4130 & 1.878610 & 2 & 5 & 1 & -1 & 39.7027 & 2.26832 & 8.710 \\
\hline 48.5930 & 1.872070 & 3 & 1 & 5 & -3 & 57.4247 & 1.60337 & -8.831 \\
\hline 48.7611 & 1.866010 & 2 & 2 & 4 & 2 & 45.3332 & 1.99881 & 3.427 \\
\hline 49.1611 & 1.851760 & 12 & 2 & 4 & -2 & 45.3332 & 1.99881 & 3.427 \\
\hline 49.2081 & 1.850100 & 6 & 6 & 2 & 0 & 48.9970 & 1.85757 & 0.211 \\
\hline 49.3409 & 1.845430 & 4 & 5 & 3 & -1 & 48.2053 & 1.88621 & 1.135 \\
\hline 49.4410 & 1.841930 & 2 & 6 & 2 & -2 & 53.3170 & 1.71679 & -3.876 \\
\hline 49.5049 & 1.839700 & 4 & 4 & 4 & 0 & 48.3781 & 1.87988 & 1.126 \\
\hline 49.8101 & 1.829140 & 5 & 4 & 4 & -4 & 64.5727 & 1.44206 & -14.76 \\
\hline 52.1551 & 1.752280 & 1 & 6 & 2 & -4 & 65.0873 & 1.4319 & -12.93 \\
\hline 52.4108 & 1.744330 & 1 & 6 & 0 & -1 & 46.1420 & 1.9656 & 6.268 \\
\hline 52.7969 & 1.732480 & 1 & 3 & 5 & 2 & 56.8662 & 1.61778 & -4.069 \\
\hline 53.5219 & 1.710710 & 8 & 3 & 5 & 4 & 56.8662 & 1.61778 & -3.344 \\
\hline 55.2331 & 1.661690 & 1 & 1 & 3 & 4 & 50.1140 & 1.81875 & 5.119 \\
\hline 60.0821 & 1.538650 & 1 & 6 & 4 & -2 & 63.7027 & 1.4596 & -3.620 \\
\hline 60.9351 & 1.519140 & 2 & 7 & 3 & -2 & 64.6936 & 1.43966 & -3.758 \\
\hline 62.1148 & 1.493090 & 3 & 5 & 5 & 4 & 72.0849 & 1.2499 & -13.97 \\
\hline 69.2000 & 1.356500 & 1 & 5 & 5 & -1 & 62.5708 & 1.48329 & 6.629 \\
\hline
\end{tabular}


are likely to modify both the behavior of steel in a corrosive medium and the nature of the metal / inhibitor interaction.

The increase in temperature has a significant effect on the formation of the inhibitor film. Indeed, a rise in temperature favors the inhibitor desorption as well as rapid dissolution of the formed organic compounds or complexes. This leads to the weakening of the corrosion resistance of the steel $^{40}$

In order to examine the influence of this parameter on the inhibitory efficiency of Bis (DL- $\alpha$-alaninato) copper dihydrate for the optimal concentration $10^{-5} \mathrm{M}$, we performed stationary electrochemical measurements in potentiodynamic mode in a temperature ranging from $298 \mathrm{~K}$ to $328 \mathrm{~K}$.

We plotted the polarization curves of steel with and without Bis (DL- $\alpha$-alaninato) copper dihydrate (Figs. 7 and 8).

In order to study the effect of temperature

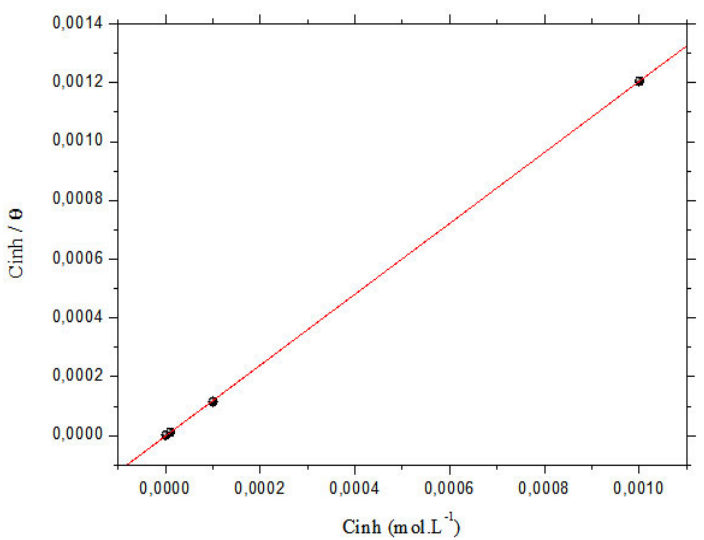

Fig. 4: Langmuir adsorption isotherm of ordinary steel in $1 \mathrm{M} \mathrm{HCl}$ in the presence of the complex at $298 \mathrm{~K}$

Table 5: The electrochemical parameters of ordinary steel in $1 \mathrm{M} \mathrm{HCl}$ at different concentrations of Bis (DL- $\alpha$-alaninato) copper dihydrate at $298 \mathrm{~K}$ on the inhibition efficiency of Bis (DL- $\alpha$-alaninato) copper dihydrate, the parameters are determined from the potentio-static polarization curves. The measurements are carried out in the absence and the presence of an inhibitor at $10^{-5} \mathrm{M}$ in the temperature range 298-328 $\mathrm{K}$. The parameters gathered in table 7 suggest that Bis (DL- $\alpha$-alaninato) copper dihydrate is well adsorbed on the surface of steel in the $1 \mathrm{M} \mathrm{HCl}$ solution at all the temperatures studied. They also show that the corrosion current density increases with increasing temperature. The increase in temperature usually accelerates the corrosion reactions which translates a dissolution of metal with a higher velocity. The inhibitory efficiency of Bis (DL- $\alpha$-alaninato) copper dihydrate increases with temperature to reach a maximum value of $88 \%$ at $298 \mathrm{~K}$ for a concentration of $10^{-5} \mathrm{M}$. The calculation of the activation parameters for the corrosion process is carried out by using the Arrhenius equations (6 and 7$)^{41}$.

$$
I_{\text {corr }}=A \exp \left(\frac{-E a}{R T}\right)
$$

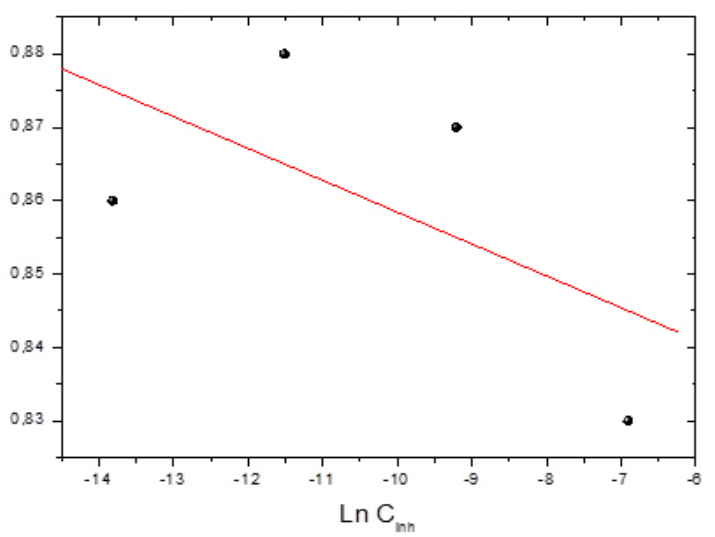

Fig. 5: Temkin adsorption isotherm of ordinary steel in $1 \mathrm{M} \mathrm{HCl}$ in the presence of the complex at $298 \mathrm{~K}$

\begin{tabular}{lllll}
\hline Concentration (M) & $E_{\text {corr }}(\mathbf{m V / A g / A g C l})$ & $i_{\text {corr }}\left(\boldsymbol{\mu A} / \mathbf{c m}^{2}\right)$ & $\beta \mathbf{c}\left(\mathbf{m V ~ d e c} \mathbf{~ d e c}^{-1}\right)$ & $\mathrm{E} \%$ \\
\hline $\mathrm{HCl} \mathrm{1M}$ & -498 & 467 & -220 & - \\
$10^{-3}$ & $-546,3$ & 81 & $-108,5$ & 83 \\
$10^{-4}$ & -573 & 63 & $-67,2$ & 87 \\
$10^{-5}$ & $-565,9$ & 57 & $-65,3$ & 88 \\
$10^{-6}$ & $-575,8$ & 65 & $-70,8$ & 86 \\
\hline
\end{tabular}


From where :

$$
\operatorname{Ln}\left(I_{\text {corr }}\right)=-\frac{E a}{R T}+\operatorname{Ln}(A)
$$

Table 6: Electrochemical impedance parameters in the absence and the presence of the complex at different concentrations

\begin{tabular}{|c|c|c|c|}
\hline $\begin{array}{l}\text { Conc. } \\
\text { (M) }\end{array}$ & $\begin{array}{c}\text { Cdl } \\
\left(\mu \mathrm{F} / \mathrm{cm}^{2}\right)\end{array}$ & $\begin{array}{c}\text { Rct } \\
(\text { ohm.cm²) }\end{array}$ & $\mathrm{E} \%$ \\
\hline $\mathrm{HCl} 1 \mathrm{M}$ & 440 & 40 & - \\
\hline $10^{-3}$ & 101 & 251 & 84 \\
\hline $10^{-4}$ & 71 & 282 & 86 \\
\hline $10^{-5}$ & 68 & 307 & 87 \\
\hline $10^{-6}$ & 72 & 278 & 86 \\
\hline
\end{tabular}

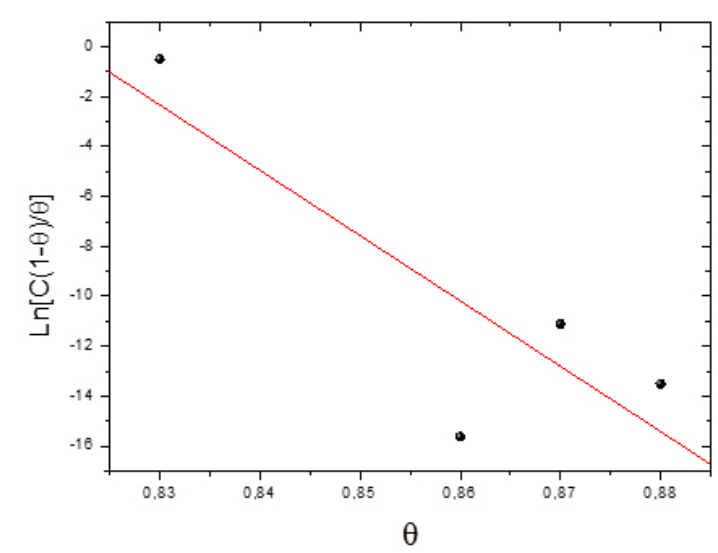

Fig.6: Frumkin adsorption isotherm of ordinary steel in $1 \mathrm{M} \mathrm{HCl}$ in the presence of the complex at $298 \mathrm{~K}$

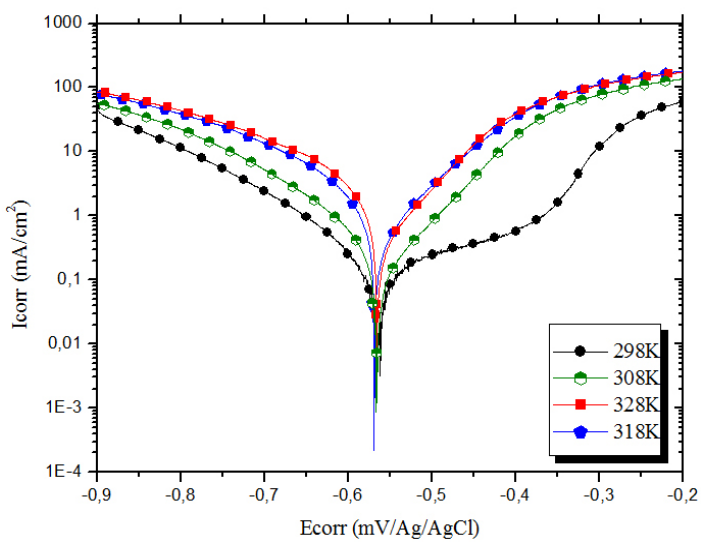

Fig. 8: The polarization curves of ordinary steel in $1 \mathrm{M} \mathrm{HCl}$ in the absence and the presence of $10^{-5} \mathrm{M}$ Bis (DL- $\alpha$-alaninato) copper dihydrate at different temperatures
Ea: the activation energy (kJ.mol-1)

$\mathrm{R}$ : the perfect gas constant (J.mol-1.K-1)

$\mathrm{T}$ : the absolute temperature $(\mathrm{K})$.

A: a pre-exponential factor.

The Enthalpy of activation $\Delta \mathrm{H}^{0}{ }_{\text {abs }}$ and activation entropy $\Delta \mathrm{S}^{0}{ }_{\text {abs }}$ determined from equations $(8 \text { and } 9)^{42,43}$ :

$$
\begin{aligned}
& \operatorname{Ln}\left(\frac{I_{\text {corr }}}{T}\right)=-\frac{\Delta H_{a b s}^{\circ}}{R T}+B \\
& I_{\text {corr }}=\frac{R T}{N h} \exp \left(\frac{\Delta S_{a b s}^{\circ}}{R}\right) \exp \left(\frac{\Delta H_{a b s}^{\circ}}{R T}\right) \\
& h: \text { Plank Constant } \\
& N: \text { Number of Avogadro }
\end{aligned}
$$

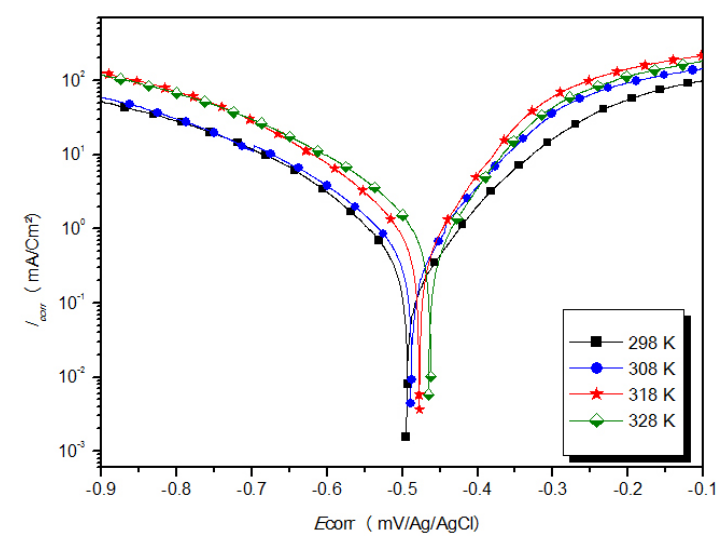

Fig.7: the potentiometric polarization curves of ordinary steel in $1 \mathrm{M} \mathrm{HCl}$ at different temperatures

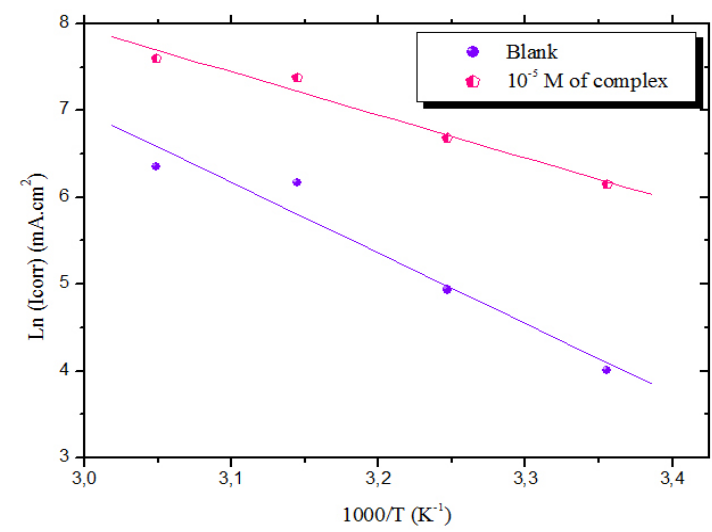

Fig. 9: Arrhenius lines calculated from the corrosion current density of steel with and without the addition of $10^{-5} \mathrm{M}$ Bis (DL- $\alpha-$ alaninato) copper dihydrate 
Fig 8 and 9 show the variation of the logarithm of the corrosion current density respectively $\mathrm{Ln}\left(\mathrm{I}_{\text {corr }}\right)$ and $\mathrm{Ln}\left(\mathrm{I}_{\text {corr }} / \mathrm{T}\right)$ of the ordinary steel in $\mathrm{HCl}$ alone and in the presence of Bis (DL $\alpha$-alaninato) copper dihydrate at different concentrations, depending on the inverse of the absolute temperature (1000 / T).

We notice that the variations $\operatorname{Ln}\left(\mathrm{I}_{\text {corr }}\right)$ $=f(1 / T)$ and $\operatorname{Ln}\left(I_{\text {corr }} / T\right)=F(1 / T)$ are substantially linear whose regression coefficient $R$ is of the order 0.97. They obey the Arrhenius law both in the absence and the presence of Bis (DL- $\alpha$-alaninato) copper dihydrate.

These results enabled us to calculate the apparent activation energies, the enthalpies and Table 7: Settings electrochemical ordinary steel corrosion in $1 \mathrm{M} \mathrm{HCl}$ at different temperature, in the absence and presence of $10^{-5} \mathrm{M}$ Bis (DL- $\alpha-$ alaninato) copper dihydrate

\begin{tabular}{|c|c|c|c|c|}
\hline Inhibitor & $\mathbf{T}(\mathrm{K})$ & $\begin{array}{l}-E_{\text {corr }}(\mathrm{mV} / \\
\mathrm{Ag} / \mathrm{AgCl})\end{array}$ & $\begin{array}{l}\operatorname{Icorr}\left(\mu \mathrm{AEI}\left({ }^{\circ}\right.\right. \\
\left.. \mathrm{cm}^{-2}\right)\end{array}$ & (\%) \\
\hline & 298 & 498 & 470 & - \\
\hline & 308 & 491 & 800 & \\
\hline \multirow[t]{3}{*}{ blank } & 318 & 475 & 1600 & - \\
\hline & 328 & 465 & 2000 & 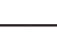 \\
\hline & 298 & 566 & 55 & 88 \\
\hline \multirow[t]{3}{*}{ complex } & 308 & 564 & 139 & 83 \\
\hline & 318 & 567 & 476 & 70 \\
\hline & 328 & 546 & 574 & 52 \\
\hline
\end{tabular}

Table 8: the activation parameters values $\Delta \mathbf{H}^{0}{ }_{\text {abs }}$ and $\Delta \mathbf{H}^{0}{ }_{\text {ads }}$ for ordinary steel in $1 \mathrm{M} \mathrm{HCl}$ in the absence and presence of $10^{-5} \mathrm{M}$ Bis (DL- $\alpha$-alaninato) copper dihydrate

\begin{tabular}{lccc}
\hline Inhibitor & $\begin{array}{c}\mathrm{Ea}(\mathrm{KJ} . \\
\left.\mathrm{mol}^{-1}\right)\end{array}$ & $\begin{array}{c}(\mathbf{K J} . \\
\left.\mathrm{mol}^{-1}\right)\end{array}$ & $\begin{array}{c}(\mathbf{J} . \\
\left.\mathbf{m o l}^{-1} \cdot \mathbf{K}^{-1}\right)\end{array}$ \\
\hline blank & 41,1 & 38,5 & $-64,40$ \\
$10^{-5} \mathrm{M}$ & 67,5 & 64,9 & 6,96 \\
\hline
\end{tabular}

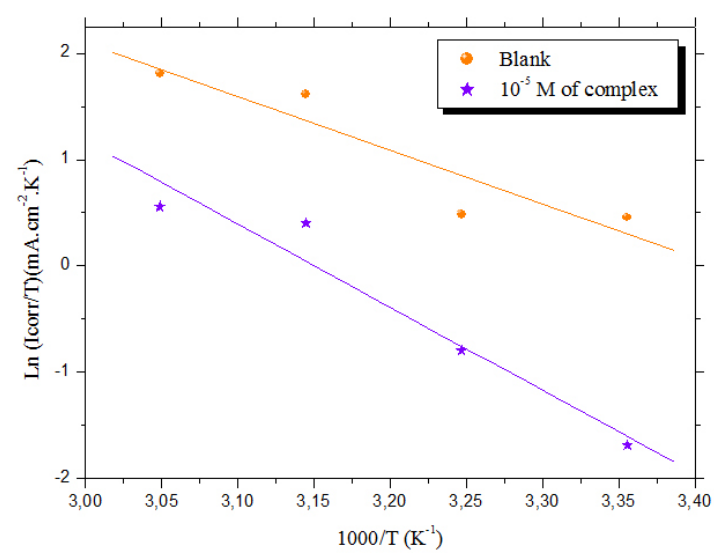

Fig.10: Variation of Ln (icorr / T) in view of the inverse of the temperature in the absence and the presence of $10^{-5} \mathrm{M}$ Bis (DL- $\alpha$-alaninato) copper dihydrate

the entropies of the ordinary steel dissolution in the absence and the presence of our inhibitor.

The values of the relative thermodynamic quantities of this inhibitor derived from Fig 8 and 9 and those obtained by using equation (8) are given in Table 8.

The studied inhibitor is adsorbed on the surface by electrostatic bonds (physisorbed on the surface of the electrode). Indeed, the Ea value for Bis (DL- $\alpha$-alaninato) copper dihydrate is greater than the Ea value which is obtained for the solution without inhibitor.

The positive signs of enthalpies $\Delta \mathrm{H}^{0}{ }_{\text {abs }}$ reflect the endothermic nature of the steel dissolution process. Indeed, the increase in the enthalpy of activation $\Delta \mathrm{H}^{0}{ }_{\text {abs }}$ with the concentration corresponds to a decrease in the dissolution of the metal ${ }^{44}$.

The value $\Delta \mathrm{S}^{0}$ ads of in the presence of the inhibitor is high and positive, which indicates an increase in the disorder involved in the formation of the metal complex /adsorbed species ${ }^{45,46}$.

\section{CONCLUSION}

We presented, in this work, the synthesis of the complexation of alanine with copper chloride hexahydrate. The structure of the complex was characterized by powder X-ray diffraction, the UVvisible spectroscopy and the infrared spectroscopy. 
The study of the corrosion inhibition of this complex was carried out by the electrochemical method (stationary and transient), which led us to conclude that:

The Bis (DL- $\alpha$-alaninato) copper dihydrate acts as an effective corrosion inhibitor for ordinary steel in $1 \mathrm{M} \mathrm{HCl}$ acid medium.

- The decrease of the concentration of the inhibitor in a corrosive medium results in a decrease in the corrosion density.

The inhibitory efficiency increases with the decrease of the concentration of the inhibitor to reach a maximum value of $88 \%$ at $10^{-5}$ $\mathrm{M}$.

- $\quad$ The displacements of the potential show that it is an inhibitor of cathodic nature.

- The adsorption of Bis (DL- $\alpha$-alaninato) copper dihydrate on the metal surface obeys the Langmuir adsorption isotherm.

\section{REFERENCES}

1. Dahmani, K.; Galai, M.; Cherkaoui, M.; El hasnaoui, A.; El Hessni, A. J. Mater. Environ. Sci. 2017, 8, 1676-1689.

2. Dahmani, K.; Galai, M.; Elhasnaoui, A.; Temmar, B.; El Hessni, A.; Cherkaoui. M. Der PharmaChemica. 2015, 7, 566-572.

3. Bert, M.; Weckhuysen, An A.; Verberckmoes,;Lijun Fu.; Robert, A.; Schoonheydt. J. Phys. Chem. 1996, 100, 9456-9461

4. Wang, Q.; Parrish, AR.; Wang, L. Expanding the genetic code for biological studies. Chem. Biol. 2009, 16, 323-336.

5. Newsholme, P.; Stenson, L.; Sulvucci, M.; Sumayao, R.; Krause. M. Amino Acid Metabolism. Comprehensive Biotechnology (Second Edition). 2011, 1, 3-14.

6. Biolo, G.; Tipton, K.-D.; Klein, S.; Wolfe R.-R. An abundant supply of amino acids enhances the metabolic effect of exercise on muscle protein. Am. J. Physiol. Endocrinol. Metab.1997, 273,122-129.

7. Lundholm, K.; Bennegard, K.; Zachrisson, H.; Lundgren, F.; Eden,E.; Moller Loswick, A.-C. Transport kinetics of amino acids across the resting human leg. J. Clin. Invest.1987, 80,763-771.

8. Jackson, G.-J.; glaseri, N. Essential amino acids, Experimental Parasitology.1973, 34, 111-114.

9. Uchida, K. Balanced amino acid composition essential for infusion-induced egg development in the mosquito (Culexpipienspallens). Journal of Insect Physiology. 1993, 39, 615-621.

10. Anderson, G.-H.; Luo, S.; Ng, L.-T. Li, E.-T.-S. Non-essential amino acid and short-term food intake of rats. Nutrition Research.1994, 14, 1179-1189,

11. Peng-peng Zhang, Jun peng, Ai-Xian, JingQuanSha, Hai-Jun Pang, Yuan Chen, Min Zhu, Yong-Hui Wang. J ournal of Molucelar Structure. 2009, 931, 50-54.

12. . Weder, J.-E.; Dillon, C.-T.; Hambley, T.-W. Copper complexes of non-steroidal antiinflammatory drugs: an opportunity yet to be realized," Coordination Chemistry Reviews. 2002, 232, 95-126.

13. Rangelov, S.; Mircheva, V. Corros. Sci.1996, 38, 301.

14. Khaled, K.-F.; Babic-Samardzija, K.; Hackerman, N. Corros. Sci. 2006, 48, 3014.

15. Singh, V.-P.; Singh, P.; Singh, A.-K. Inorg. Chim.Acta. 2011, 379, 56.

16. Kiruthikajothi, K.; Chandramohan, G.; Jayabharathi, G. ChemSci Rev Lett. 2014, 3, 603-607

17. Mansouri, K.; Saidi, M. ; Dakmouche, M. Inhibition de la Corrosion de l'Acier au Carbone X-52 dans un Milieu H2SO4 (20\%) par 3-Méthyle-Thio-4- Tolyl-1,2-Dithiolylium, Contre Anion $\left(\mathrm{CH}_{3} \mathrm{SO}_{4}^{-}\right)$, J. Adv. Res. Sci. Technol. 2015, 2, 130-138.

18. Ropital, F. Current and future corrosion challenges for a reliable and sustainable development of the chemical, refinery, and petrochemical industries, mater. Corros.2009, 60, 495-500.

19. Finšgar, M.; Jackson, J. Application of corrosion inhibitors for steels in acidic media for the oil and gas industry: A review, Corros. Sci. 2014, 86, 17-41. 
20. Galai, M.; Rbaa, M.; El Kacimi, Y.; Ouakki, M.; Dkhirech, N.; Touir, R.; Lakhrissi, B.; EbnTouhami, M. Anal.Bioanal.Electrochem. 2017, 9, 80-101.

21. Lebrini, M.; Robert, F.; Vezin, H.; Roos, C. Electrochemical and quantum chemical studies of some indole derivatives as corrosion inhibitors for C38 steel in molar hydrochloric acid.Corros. Sci. 2010, 52, 3367-3376.

22. Galai, M.; El Gouri, M.; Dagdag, O.; El Kacimi, Y.; Elharfi, A.; Ebn Touhami, M.; J. Mater. Environ. Sci. 2016, 7, 1562.

23. El Hezzat, M.; Zarrok, H.; Benzekri, Z.; El Assyry, A.; Boukhris, S.; Souizi, A.; Galai, M.; Touir, R.; Ebn Touhami, M.; Oudda, H.; Zarrouk, A.Der Pharmacia Lettre. 2015, 7 , 239.

24. Decombe, J.; Se, C. R. ances Sci. Acad.1933, 196, 866.

25. Bellamy, L.-J. the Infrared Spectra of complexes Molecules, $3^{\text {th }}$ Ed; Wiley New York.1975, 226.

26. Saxena, V.-K.; Srivastava, M.-N. Synt.React. Inorg.Met.Org.Chem. 1996, 26, 16.

27. Marcu, A.; Stanila, A.; Cozar, O.; David, L. Journal of optoelectronics and materials. 2008, 10, 830-833.

28. Adkhis, A.; Benali-baitich, O.; Khan, M.-A;. Bouet, G. J.Soc.Alger.Chim. 2003, 13, 239250.

29. Hassan, A.-M.-A. J. Istanic Acad. Sci.1991, 4, 271.

30. Patel, M.; Patel, M.; Ray, A.; Patel, H. J. Inorg. Nucl.Chem. 1981, 43, 509.

31. Baran, E.-J.; Wagner, C.-C.; Torre, H. Bioz, J. Chem. Soc.2002, 13, 576.

32. Watt, G.-W.; Klett, D.-S. Inorg.Chem.1966, 5, 1278.

33. Masoud, M S.;.Amira, M F.; Ramadan, A M. ; El-Ashry, G M.;. SpectrochimicaActa Part A. 2008, 69, 230-238.
34. Sawant, V.-A.; Gotpagar, S.-N.; Yamamgar, B.-A.; Sawant, S.-K.; Kankariya, R.-D.; Chavan, S.-S. SpectrochimicaActa Part A. 2009, 72, 663-669.

35. Kirik, S.; Golovnev, N. Inst. of Chemistry, Krasnoyarsk, Russian Federation. ICDD Grant-in-Aid. 2005.

36. Hitchman, M. J. Chem. Soc., Dalton Trans. 1987, 457.

37. Serrar, H.; Belayachi,M.; Zarrouk ,A.; Oudda ,H.; EbnTouhami, M.; El Hezzat, M.; Boukhris, S.; Souizi , A.; Galai, M.Der Pharmacia Lettre. 2013,5,173.

38. Prabhu, R.-A. ; Venkatesha, T.-V. ; Shanbhag, A.-V.; Kulkarni, G.-M. ; Kalkhambkar, R.-G. Corros. Sci. 2008, 50,3356.

39. Biligç, S. ;Çaliskan, N. Appl.Surf. Sci. 1999, 152,107.

40. Benabida, A.; Galai, M.; Cherkaoui, M.; Dagdag, O. Anal. Bioanal.Electrochem. 2016,8, 962-976.

41. Moretti, G.; Quartarone, G.; Tassanet, A.; Zingales, A. Electrochim.acta.1996, 41, 1971.

42. El Ouali, B.; Hammouti, B.; Aouiniti, A.; Ramli, Y.; Azougagh, M.; Essasi, E.-M.; Bouachrine, M. J. Mater.Environ. Sci., 2010, $1,1$.

43. Guan, N.-M.; Xueming, L.; Fei, L. Mater. Chem. Phys. 2004, 86, 59-68.

44. Tazouti, A.; Galai, M.; Touir, R.; EbnTouhami, M.; Zarrouk, A.; Ramli, Y.; Saraçoðlu, M.; Kaya, S.; Kandemirli, F.; Kaya, C.Journal of Molecular Liquids. 2016, 221, 815-832.

45. Alaoui, K.; El Kacimi, Y.; Galai, M.; Dahmani, K.; Touir, R.; El Harfi, A.; EbnTouhami, M.; Anal. Bioanal.Electrochem. 2016, 8, 830.

46. Tiskar, M.; Galai, M.; Elhadiri, H.; EbnTouhami, M.; Sfaira, M.; Satrani, B.; Ghanmi, M.; Chaouch, A.; Touir, R. Matériaux\& Techniques. 2016, 104, 609. 